\title{
Hereditary angioedema in childhood
}

\author{
Young Min Ahn, MD, PhD
}

Department of Pediatrics, Eulji Hospital , Eulji University, Seoul, Korea

Angioedema (AE) is defined as deep dermal/subcutaneous tissue swelling with localized increased permeability of the blood vessels mediated by mast cell mediators including histamine and bradykinin. ${ }^{1,2)}$ Distinct from major histamine-mediated $\mathrm{AE}$, bradykinin-mediated $\mathrm{AE}$ is not associated with urticarial wheal; rather, it is caused by a hereditary deficiency/defect of $\mathrm{C} 1$-inhibitor (C1-INH) or acquired by drug exposure or other mechanisms. $\left.{ }^{2}\right)$ Hereditary AE (HAE) is a rare autosomal dominant bradykinin-mediated $\mathrm{AE}$, but a family history may not be present in up to $25 \%$ of patients (those with de novo mutation). ${ }^{2,3)}$ Its incidence is reportedly 1:50,000-100,000 in Caucasians, much higher than that in Japanese, Chinese, and Koreans; the first nationwide survey identified a total of 65 patients by 2016 with an estimated prevalence was $1.3 / 1,000,000 .{ }^{4)}$ Of them, 44 (67.7\%) were female; 37 (58.7\%) had a family history of HAE. Of the cohort, $90.8 \%$ had a C1INH deficiency (HAE type I) and 9.2\% had C1-INH dysfunction (HAE type II), but other mutations with normal C1-INH level and function are yet to be identified. Furthermore, the clinical manifestation and severity of HAE may vary among ethnicities, resulting in a milder severity, higher proportion of asymptomatic patients, and later age at onset in Asians than in Europeans. ${ }^{4)}$ Most patients experience their first attacks in childhood or adolescence, after which point the frequency of attacks increases; for example, in Germany, 51.2\% of patients experienced their first HAE symptoms before 10 years of age, $37.8 \%$ in the second decade, and $12 \%$ after 20 years of age versus only $26.2 \%$ of patients in Korea. ${ }^{4,5)}$ An early symptom onset may predict a more severe subsequent disease course. ${ }^{5,6}$

Our case has some interesting clinical points. ${ }^{7)}$ First, the patient's initial presentation was a pruritic erythema marginatumlike rash, followed by fever, abdominal pain, and $\mathrm{AE}$ on the hands and feet the next day. Fortunately, we did not miss the patient's medical history of recurrent arm swelling for one year and checked her complement level, which led to confirmation of the diagnosis without delay at 4 years of age. HAE does not accompany pruritis or urticarial wheal, but it shows erythema marginatum-like prodromal skin rashes in $60 \%$ of cases that can interfere with and delay the HAE diagnosis by years. ${ }^{8)}$ Second, the patient's mother developed symptoms of HAE 5 years later during breast cancer chemotherapy. HAE can be fatal due to laryngeal or gastrointestinal involvement, so its early diagnosis and treatment are essential. ${ }^{2)}$ The reported mean delay to diag. nosis after the initial presentation was $8-13$ years, but this patient and her mother were diagnosed without delay. The World Allergy Organization/European Academy of Allergy and Clinical Immunology (WAO/EAACI) guidelines for $\mathrm{HAE}^{2)}$ recommend that all patients with suspected HAE undergo the assessment of serum levels of C4 and C1-INH proteins as well as C1-INH function. If any of the levels are abnormally low, the tests should be repeated to confirm the diagnosis of HAE. The WAO/EAACI guidelines also recommend that all family members, including grandparents, parents, siblings, children, and grandchildren of HAE-1/2 patients, be screened due to the possibility of autosomal dominant inheritance and delayed diagnosis leading to morbidity, since the first $\mathrm{AE}$ event can be fatal due to airway involvement. Therefore, when a patient has suspected HAE at 4 years of age, the test should be repeated for confirmation and family screenings should be performed immediately. All early testing performed for the offspring of HAE-1/2 patients should be repeated after 1 year of age; the measurement of $\mathrm{C} 4$ was not useful for diagnosing HAE-1/2 in children younger than 12 months since C4 levels are frequently low in healthy infants. However, genetic testing increases the diagnostic reliability in children and may be helpful.2)

Third, in our case, AE did not recur after the first admission, and the recurrent abdominal pain improved spontaneously after 6 years of age; her mother's symptoms disappeared after the discontinuation of tamoxifen, suggesting mild severity despite the early age at onset. ${ }^{7)}$ However, HAE is known to worsen around puberty and persist throughout life with unpredictable severity. ${ }^{5)}$ This case should be followed closely according to the recommendation that all patients have an action plan, avoid possible triggers that may induce HAE attacks, and be taught to self-administer medications. ${ }^{2,6}$ The treatment of HAE is divided into treatments for acute attacks; maintenance therapy (longterm prophylaxis); and preprocedural prophylaxis (short-term prophylaxis) for surgical trauma, dental surgery, and endoscopy. All patients must have sufficient medication for the on-demand treatment of 2 attacks and carry on-demand medication at all times. ${ }^{2,6)} \mathrm{C} 1-\mathrm{INH}$ should be used to treat HAE attacks in children under the age of 12 years. ${ }^{6}$ In Korea, C1-INH and

Corresponding author: Young Min Ahn, MD, PhD. Department of Pediatrics, Eulji Hospital, Eulji University, 68, Hangeulbiseok-ro, Nowon-gu, Seoul, Korea 凶E-mail: aym3216@eulji.ac.kr, https://orcid.org/0000-0002-1697-8041

Received: 24 September, 2019, Revised: 31 December, 2019, Accepted: 7 January, 2020

This is an open-access article distributed under the terms of the Creative Commons Attribution Non-Commercial License (http://creativecommons.org/licenses/bync/4.0/) which permits unrestricted non-commercial use, distribution, and reproduction in any medium, provided the original work is properly cited.

Copyright (c) 2020 by The Korean Pediatric Society 
bradykinin $\mathrm{B}_{2}$ receptor antagonist icatibant ( $\geq 2$ years of age) are available, while the oral kallikrein inhibitor for long-term prophylaxis is currently in clinical trial. ${ }^{9)}$

See the article "Complement 4 levels of a 4-year-old girl with angioedema" in Volume 63 on page 30.

\section{Conflicts of interest}

No potential conflict of interest relevant to this article was reported.

\section{References}

1. Zuberbier T, Aberer W, Asero R, Abdul Latiff AH, Baker D, BallmerWeber B, et al. The EAACI/GA²LEN/EDF/WAO guideline for the definition, classification, diagnosis and management of urticaria. Allergy 2018;73:1393-414.

2. Maurer M, Magerl M, Ansotegui I, Aygören-Pürsün E, Betschel S, Bork
$\mathrm{K}$, et al. The international WAO/EAACI guideline for the management of hereditary angioedema-The 2017 revision and update. Allergy 2018;73: 1575-96.

3. Bernstein JA, Cremonesi P, Hoffmann TK, Hollingsworth J. Angioedema in the emergency department: a practical guide to differential diagnosis and management. Int J Emerg Med 2017;10:15.

4. Jung JW, Suh DI, Park HJ, Kim S, Kwon HS, Yang MS, et al. Clinical features of hereditary angioedema in Korean patients: a nationwide multicenter study. Int Arch Allergy Immunol 2018;176:272-9.

5. Bork K, Meng G, Staubach P, Hardt J. Hereditary angioedema: new findings concerning symptoms, affected organs, and course. Am J Med 2006;119:267-74.

6. Farkas H, Martinez-Saguer I, Bork K, Bowen T, Craig T, Frank M, et al. International consensus on the diagnosis and management of pediatric patients with hereditary angioedema with $\mathrm{C} 1$ inhibitor deficiency. Allergy 2017;72:300-13.

7. Shin S, Lee YT, Lee KY, Park J, Lee JH, Yang EA. Complement 4 (C4) levels in 4-year-old girl with angioedema. Clin Exp Pediatr 2020;63:30-1.

8. Magerl M, Doumoulakis G, Kalkounou I, Weller K, Church MK, Kreuz W, et al. Characterization of prodromal symptoms in a large population of patients with hereditary angio-oedema. Clin Exp Dermatol 2014;39:298303.

9. Farkas H, Köhalmi KV. Icatibant for the treatment of hereditary angioedema with C1-inhibitor deficiency in adolescents and in children aged over 2 years. Expert Rev Clin Immunol 2018;14:447-60. 